\title{
Produção da piscicultura de espécies nativas da Amazônia em Rondônia
}

\author{
Ricardo Gomes de Araújo Pereira ${ }^{1}$
}

\section{Resumo}

Este estudo teve como objetivo analisar a piscicultura do estado de Rondônia, procurando descrever a sua situação atual destacando a produção no setor e seu potencial. O estado de Rondônia tem apresentado uma produção de pescado altamente significativa levando-se em consideração que a cultura vem sendo implantada nos últimos 30 anos. Rondônia é o maior produtor de peixe em cativeiro do Brasil sendo ainda o maior produtor das espécies tambaqui (Colossoma macropomum, Cuvier, 1818), e pirarucu (Arapaima gigasem). Para a realização desta pesquisa utilizou-se a técnica de coleta de dados de documentação indireta voltada para a pesquisa de dados secundários, consultando e analisando diversos bancos de dados disponibilizados principalmente pela Agência de Defesa Sanitária Agrosilvopastoril do Estado de Rondônia-IDARON. A produção total em 2017 foi de 153.540 t., sendo esta produção 63.383 t., oriunda de propriedades com menos de 5 ha., de lâmina d'água e 90.157 t., vindas de produtores com mais de 5 ha. Esta produção é oriunda de 35.580 e 4.157 propriedades respectivamente. O estado de Rondônia apresenta potencial para dobrar sua produção levando-se em consideração os investimentos já realizados em propriedades que o produtor não comercializa a produção

Palavras-chaves: Tambaqui. Pirarucu. Pescado Nativo.

\section{Production of fish farming of native Amazonian species in Rondônia}

\begin{abstract}
The aim of this study is to analyze fish farming in the state of Rondônia, seeking to describe its current situation, highlighting production in the sector and your potential. The state of Rondonia has presented a highly significant fish production taking into consideration that the culture has been implanted in the last thirty years. Rondônia is the largest captive fish producer in Brazil and still the largest producer of tambaqui species (Colossoma macropomum, Cuvier, 1818), and pirarucu (Arapaima gigasem). For the accomplishment of this research it was used the technique of data collection of indirect documentation directed to the search of secondary data, consulting and analyzing several databases made available mainly by the Agrosilvopastoril Sanitary Defense Agency of the State of Rondônia-IDARON. Total production in 2017 was 153,540T. This production is 63,383T., Coming from properties with less than 5 ha., From water slide and 90,157T., coming from producers with more than 5 ha. This production comes from 35,580 and 4,157 properties respectively. The state of Rondônia has the potential to double its production considering the investments already made in properties that the producer does not sell the production.
\end{abstract}

Keywords: Tambaqui. Pirarucu. Fish Native.

\footnotetext{
${ }^{1}$ Zootecnista, D.Sc. EMBRAPA CPAF-RO. Porto Velho, RO. Brasil.

https://orcid.org/0000-0002-9040-4070

Autor para correspondência: ricardo.pereira@embrapa.br.
}

Recebido para publicação em 01 de novembro de 2019. Aceito para publicação em 05 de janeiro de 2020.

e-ISSN: 2447-6218 / ISSN: 2447-6218. Atribuição CC BY. 


\section{Introdução}

O Brasil tem 7.491 quilômetros de extensão litorânea, sendo o quinto país do mundo em extensão territorial, com $8.514 .876 \mathrm{~km}^{2}$. O país importou no ano de 2017, 374.290 t. de peixe e exportou 34.583 t., ANUALPEC (2018). O país ainda se destaca por possuir $12 \%$ do total de reserva de água doce do planeta (Agência Nacional das Águas 2019), concentrada principalmente na região Amazônica. Com relação ao consumo, pela primeira vez, a marca de $20 \mathrm{~kg} / \mathrm{hab} / \mathrm{ano}$. No Brasil, o consumo foi de $9,6 \mathrm{~kg} /$ ano em 2015. (FAO, 2019). No país a tendência é de aumento no consumo, entretanto a oferta de peixe em cativeiro é reduzida principalmente para a população de baixa renda.

Há poucas décadas achava-se que muitas espécies de peixes estariam fadadas a extinção porque não se dominava a tecnologia de criação e principalmente reprodução em cativeiro. As espécies nativas eram as mais ameaçadas sendo reduzido o tamanho e peso para o abate. Com o desenvolvimento de tecnologias nas áreas de reprodução e criação, mudou o cenário e o produtor de peixes em Rondônia investiu para que se tenha hoje o Estado como referencia nacional na produção de pescado nativo da região Amazônica. Com o aumento da população na região, principalmente com a zona franca de Manaus e nas capitais como: Belém-PA, Porto Velho-RO e Rio Branco (AC), as reservas de pescado, principalmente tambaqui e pirarucu, foram reduzindo a números que comprometiam as espécies citadas. As técnicas de produção de alevinos em laboratórios e a criação dessas espécies em cativeiro possibilitou preservar a produção nas bacias hidrográficas e aumentar significativamente a oferta de pescado para toda a Região Norte, outros estados da federação e para exportação.

O estado de Rondônia tem apresentado uma produção de pescado altamente significativa, principalmente levando-se em consideração que a cultura vem sendo implantada nos últimos 30 anos. Atualmente, o Estado é o maior produtor de peixe em cativeiro do Brasil sendo ainda o maior produtor da espécie tambaqui (Colossoma macropomum, Cuvier, 1818), e pirarucu (Arapaima gigasem) em tanque escavado, tendo como principais polos o Vale do Jamari e a Região Central do Estado de acordo com o (Anuário Peixe BR da Piscicultura, 2019).

A bacia hidrográfica do estado de Rondônia tem uma significativa contribuição no contexto da Bacia Amazônica e está inserida numa área fluvial com extensão de $1.500 \mathrm{~km}$, com destaque para os rios Madeira, Mamoré, Guaporé e seus principais afluentes, constituindo-se, assim, em uma região possuidora de um excelente manancial hídrico, com grande potencial de recursos naturais aptos para serem explorados racionalmente.

A produção de peixe em Rondônia mudou o cenário das propriedades rurais e vem cada vez mais interferindo na oferta de um pescado de qualidade onde se destaca a capacidade do produtor em investir nesta cadeia produtiva. Estes investimentos têm interferido diretamente na vida da população rondoniense. Em 2011, o Estado produziu 39.700 t. de tambaqui e 1.300 t. de pirarucu (SEBRAE AGRONEGÓCIOS, 2014). A comercialização dessa produção representou um faturamento de R\$ 160 milhões para o setor, sendo Manaus o principal mercado consumidor. Segundo dados do IBGE. Em 2014 foram produzidas 71.000 t., em 11,9 mil há, de lâmina d'água representando $78 \%$ de aumento em relação ao ano de 2010 .

Trabalhando com produtores de tambaqui em propriedades familiares onde cerca de $84 \%$ dos empreendimentos visitados possuíam menos de 5 há de lâmina d'água Meante e Dória (2017) observaram uma produção média de 7,8 t/há em sistema semi intensivo.

Segundo Silva e Araujo (2017) a piscicultura em Rondônia ainda depende de fatores como a limitada capacidade de processamento, os elevados custos de produção e as limitações zootécnicas onde problemas de sanidade têm causado prejuízos zootécnicos e econômicos.

Este estudo teve como objetivo analisar a piscicultura do estado de Rondônia, procurando descrever a sua situação atual destacando a produção no setor e seu potencial.

\section{Material e métodos}

Para a realização desta pesquisa utilizou-se a técnica de coleta de dados de documentação indireta voltada para a pesquisa de dados secundários, consultando e analisando diversos bancos de dados disponibilizados principalmente pela Agência de Defesa Sanitária Agrosilvopastoril do Estado de Rondônia-IDARON. Os dados são fornecidos pelo IDARON que possui cadastro individual de cada propriedade com visita dos técnicos onde são tabulados os dados de produção e comercialização. A cada venda é emitido guia de transporte animal (GTA) e o controle da produção se da por este documento. A lâmina de água por hectare é informada por cada produtor além da quantidade de peixe e a espécie. Com estas informações é possível avaliar-se os dados utilizados neste trabalho.

Segundo a classificação de Koppen, o estado de Rondônia apresenta clima tropical chuvoso, do tipo Aw, Clima Tropical Chuvoso que se caracteriza por total pluviométrico anual e moderado período de estiagem. O Estado possui uma área de $237.765,233 \mathrm{~km}^{2}$ e uma população de 1.757.589 pessoas, distribuídos em 52 municípios. O clima de Rondônia caracteriza-se por apresentar uma homogeneidade espacial e sazonal da temperatura média do ar. Estando sob a influência do clima tropical chuvoso, a média anual da precipitação pluvial varia entre 1400 e 2600 milímetros ao ano e mais de $90 \%$ desta ocorre na 
estação chuvosa. A média anual da temperatura do ar gira em torno de $24^{\circ} \mathrm{C} \mathrm{e} 26^{\circ} \mathrm{C}$, com temperatura máxima entre $30^{\circ} \mathrm{C}$ e $35^{\circ} \mathrm{C}$, e mínima entre $16^{\circ} \mathrm{C}$ e $24^{\circ} \mathrm{C}$. A média anual da umidade relativa do ar varia de $80 \%$ a $90 \%$ no verão, e em torno de $75 \%$, no outono e no inverno. O período chuvoso ocorre entre os meses de outubro e abril, e o período seco entre maio e agosto. A insolação é de aproximadamente 1770 h e a evaporação está acima de $750 \mathrm{~mm}$.

\section{Resultados e discussão}

Analisando dados fornecidos pela Agência de Defesa Agrosilvopastoril do Estado de Rondônia (IDARON) declarados pelos piscicultores no período 15/10/17 a 15/11/17. A Figura 1 apresenta as principais espécies produzidas em cativeiro em Rondônia, produção de peixes, lâmina d'água em ha e número de produtores que comercializam ou não sua produção. Rondônia possui um numero total de 7.258 produtores perfazendo uma lâmina d'água de 9.301 ha., sendo que 1.636 produtores com lâmina de 5.516 ha., que respondem por $59,31 \%$ comercializam sua produção enquanto 5.622 produtores com lâmina de 3.785 ha., respondem por $40,69 \%$ não comercializam sua produção quantidade total é de 26,513 milhões de peixes sendo $78,37 \%$ para os que comercializam e 21,13\% para os que não comercializam. As espécies mais produzidas são o tambaqui com uma lâmina d'água de 6.789 ha., pintado surubim e cachara 1.293 ha., tilápia 778 ha., pirarucu 726 ha., e jatuarana 318 ha.

Figura 1 - Principais espécies produzidas em cativeiro em Rondônia

\begin{tabular}{|c|c|c|c|c|c|c|c|c|c|c|c|c|c|}
\hline \multicolumn{2}{|c|}{ Produtores } & \multirow{2}{*}{\begin{tabular}{|c|} 
Lâmina de água (ha) \\
3.785
\end{tabular}} & \multirow{2}{*}{\begin{tabular}{|l|} 
Quant. Peixes \\
5.601 .412 \\
\end{tabular}} & \multirow{2}{*}{$\begin{array}{r}\text { Tambaqui } \\
5.204\end{array}$} & \multirow{2}{*}{$\begin{array}{c}\begin{array}{c}\text { Pintado/ } \\
\text { Surubim/ } \\
\text { Cachara }\end{array} \\
1.045 \\
\end{array}$} & \multirow{2}{*}{$\begin{array}{r}\text { Pirarucu } \\
455\end{array}$} & \multirow{2}{*}{$\begin{array}{c}\text { Tilápia } \\
690\end{array}$} & \multirow{2}{*}{\begin{tabular}{|c|} 
Jatuarana \\
224
\end{tabular}} & \multirow{2}{*}{$\frac{\text { Piauçu }}{180}$} & \multirow{2}{*}{$\begin{array}{r}\text { Curimba } \\
52\end{array}$} & \multirow{2}{*}{\begin{tabular}{|c|} 
Pirapitinga \\
52 \\
\end{tabular}} & \multirow{2}{*}{$\frac{\text { Patinga }}{67}$} & \multirow{2}{*}{$\begin{array}{r}\text { Carpa } \\
53\end{array}$} \\
\hline \multirow{2}{*}{ Não Comercializam } & \multirow{2}{*}{5.622} & & & & & & & & & & & & \\
\hline & & $40,69 \%$ & $21,13 \%$ & $92,56 \%$ & $18,59 \%$ & $8,09 \%$ & $12,27 \%$ & $3,98 \%$ & $3,20 \%$ & $0,92 \%$ & $0,92 \%$ & $1,19 \%$ & $0,94 \%$ \\
\hline \multirow{2}{*}{ Comercializam } & \multirow{2}{*}{1.636} & 5.516 & 20.911 .807 & 1.585 & 248 & 271 & 88 & 94 & 47 & 27 & 10 & 14 & 7 \\
\hline & & $59,31 \%$ & $78,87 \%$ & $96,88 \%$ & $15,16 \%$ & $16,56 \%$ & $5,38 \%$ & $5,75 \%$ & $2,87 \%$ & $1,65 \%$ & $0,61 \%$ & $0,86 \%$ & $0,43 \%$ \\
\hline \multirow{2}{*}{ Total } & \multirow{2}{*}{7.258} & \multirow{2}{*}{9.301} & \multirow{2}{*}{ 26.513.219 } & 6.789 & 1.293 & 726 & 778 & 318 & 227 & 79 & 62 & 81 & 60 \\
\hline & & & & $93,54 \%$ & $17,81 \%$ & $10,00 \%$ & $10,72 \%$ & $4,38 \%$ & $3,13 \%$ & $1,09 \%$ & $0,85 \%$ & $1,12 \%$ & $0,83 \%$ \\
\hline
\end{tabular}

Fonte: IDARON (2018).

A produção total em 2017 foi de 153.540 t., sendo esta produção 63.383 t., oriunda de propriedades com menos de 5 ha., de lamina d'água e 90.157 t., vindas de produtores com mais de 5 ha, (Pereira et al., 2019). Essas produções estão de acordo com as observadas por Silva e Araujo (2017) e Meante e Dória (2017).

As exportações de peixe produzido em Rondônia tiveram início em 2017 com destino ao Vietnã, segundo dados do ComexStat. Em 2019, de janeiro a junho já foram exportados mais de 259 toneladas de peixe para o Peru, Bolívia. Além da exportação que se inicia no estado, Rondônia vem abastecendo os estados do Pará, Distrito Federal, Goiás, Mato Grosso do Sul, São Paulo, Tocantins, Rio de Janeiro e Acre tendo como principal parceiro o estado do Amazonas, (Figura 2). Essa tendência de aumento das exportações, puxada pelo câmbio favorável, mas também pela maior demanda internacional de alimentos e, particularmente, pelo aumento do consumo foi observada por Schulter e Vieira Filho (2017).

Nos últimos três anos segundo dados da Secretaria de Estado de Desenvolvimento Ambiental (Sedam), a área total destinada a piscicultura no estado de Rondônia cresceu 8,63\%, (SEAGRI, 2019). Este aumento de áreas alagadas onde são produzidos os pescados tem acontecido sucessivamente o que garante uma elevação na produção de pescado e maior capacidade de exportação. Provavelmente o fato dos empreendimentos estarem concentrados em duas regiões produtoras uma na região central e a outra no Vale do Jamari tenha sido um facilitador para o desenvolvimento da piscicultura.

A implantação da cadeia produtiva no estado intensificou o uso de rações comerciais com a implantação de fábricas, priorização de espécies autóctones da Amazônia, uso intensivo de equipamentos nos sistemas de criação, abertura de mercados internos e externos e aumento de emprego e renda.

\section{Conclusões}

A piscicultura em Rondônia é destaque nacional na produção de peixe em cativeiro tendo garantido emprego e renda para os produtores do Estado e a população em geral ao longo de toda sua cadeia produtiva.

O estado de Rondônia apresenta potencial para dobrar sua produção levando-se em consideração as condições edafoclimáticas, os investimentos já realizados em propriedades onde o produtor não comercializa a produção. 
Pereira, R. G. A.

Figura 2 - Destinos da venda de pescado para os estados no ano de 2018

\begin{tabular}{ccccc}
\hline UF & Destino & \%GTA & Abate & Kg Peixe \\
\hline AC & 19 & $1,0 \%$ & 175.200 & $1,0 \%$ \\
AM & 580 & $30,7 \%$ & 7.034 .916 & $41,2 \%$ \\
AP & 2 & $0,1 \%$ & 23.000 & $0,1 \%$ \\
BA & 10 & $0,5 \%$ & 81.000 & $0,5 \%$ \\
DF & 140 & $7,4 \%$ & 1.520 .158 & $8,9 \%$ \\
GO & 126 & $6,7 \%$ & 1.112 .618 & $6,5 \%$ \\
MA & 13 & $0,7 \%$ & 87.120 & $0,5 \%$ \\
MS & 44 & $2,3 \%$ & 316.266 & $1,9 \%$ \\
PA & 154 & $8,1 \%$ & 1.479 .130 & $8,7 \%$ \\
RO & 766 & $40,5 \%$ & 4.904 .215 & $28,7 \%$ \\
RJ & 1 & $0,1 \%$ & 12.000 & $0,1 \%$ \\
SP & 35 & $1,9 \%$ & 311.315 & $1,8 \%$ \\
TO & 1 & $0,1 \%$ & 4.700 & $0,0 \%$ \\
\hline TOTAL & 1891 & $100,0 \%$ & 17.061 .638 & $100,0 \%$ \\
\hline
\end{tabular}

Fonte: IDARON (2018)

A produção de peixe em Rondônia mudou o cenário das propriedades rurais e intensificou o uso de rações comerciais com a implantação de fábricas, priorização de espécies autóctones da Amazônia, uso intensivo de equipamentos nos sistemas de criação, abertura de mercados internos e externos e aumento de emprego e renda.

\section{Referências}

Agência Nacional das Águas. 2019. O país ainda se destaca por possuir $12 \%$ do total de reserva de água doce do planeta. Disponível em: https://www.ana.gov.br/noticias-antigas/brasil-tem-cerca-de-12-dasreservas-mundiais-de-a.2019-03-15.1088913117.

ANUALPEC -Anuário da Pecuária Brasileira.2018. Importação de peixe. São Paulo: FNP, v.1.

Anuário Peixe BR. 2019. Disponível em: https://www.peixebr.com.br/ anuario-peixe-br-da-piscicultura-2019/.

IDARON - Agência de Defesa Sanitária Agrosilvopastoril do Estado de Rondônia. Informe semestral de campo: referente às etapas de vacinação de 2018. Porto Velho, RO, março, 2018, não paginado.

Meante, R.; Dória C. 2017. Caracterização da cadeia produtiva da piscicultura no estado de Rondônia: desenvolvimento e fatores limitantes. Revista de Administração e Negócios da Amazônia, 9:164 181. Doi: https://doi.org/10.18361/2176-8366/rara.v9n4p164-181.

FAO-OMS. Organización de lãs Naciones Unidas para la Alimentación y la Agricultura-. 2016. El estado mundial de la pesca y la acuicultura 2016 - Contribución a laseguridad alimentaria y lanutrición para todos. Roma, 224 pp. Disponível em: http://www.fao.org/3/a-i5555s.pdf.

Pereira, R. G. de A.; Santos, F. A.; Azevedo, E. S. 2019. Situação atual da piscicultura em cativeiro no estado de Rondônia. Anais do XXI Congresso Brasileiro de Engenharia de Pesca. Manaus, AM. Outubro de 2019. Disponível em: http://www.conbep.com.br/.
Rondônia. Lei no 3.437, de 9 de setembro de 2004. Dispõe sobre a Aquicultura no Estado de Rondônia e dá outras providências. Diário Oficial do Estado de Rondônia, 9 de setembro de 2014.

Schulter, E. P.; Vieira Filho, J. E. R. 2017. Evolução da piscicultura no Brasil: diagnóstico e desenvolvimento da cadeia produtiva de tilápia. Texto para discussão / Instituto de Pesquisa Econômica Aplicada. Rio de Janeiro : Ipea. Disponível em: http://www.ipea.gov.br/portal/images/ stories/PDFs/TDs/td_2328.pdf.

SEAGRI. Secretaria de Estado da Agricultura. Capacidade de produção da piscicultura em Rondônia. Disponível em: http://www.rondonia.ro.gov. $\mathrm{br} /$ capacidade-de-producao-da-piscicultura-em-rondonia-cresceu-863segundo-dados-da-sedam. Acesso em 22de junho de 2019.

Sebrae Agronegócios. 2014. A importância da qualidade da água na piscicultura. Disponível em: https://respostas.sebrae.com.br/aimportancia-da-qualidade-da-agua-na-piscicultura/.

Silva, F; Araujo, L. 2017.A piscicultura de Rondônia: avanços e perspectivas. Anais do Congresso da Sociedade Brasileira de Economia, Administração e Sociologia Rural. Santa Maria, RS, 55. Disponível em: https://www.alice.cnptia.embrapa.br/alice/bitstream/doc/1075073/1/ PISCICULTURADERONDONIA.pdf. 